\title{
Good intentions gone wrong: did conservation management threaten Endangered huemul deer Hippocamelus bisulcus in the future Patagonia National Park?
}

\author{
Heiko U. Wittmer, L. Mark Elbroch and Andrew J. Marshall
}

\begin{abstract}
Conservation interventions increasingly involve active management of relative species abundances, especially when taxa of conservation concern are threatened by complex food web interactions. Unfortunately, the complexity of such interspecific interactions means that well-meaning management interventions can have unexpected, sometimes detrimental, effects on the species they are intended to protect. Here we report that the abrupt removal of an abundant non-native prey species (domestic sheep) and the cessation of predator control, actions intended to protect huemul deer Hippocamelus bisulcus in the future Patagonia National Park, appear to have had negative effects on this Endangered ungulate. During and following the changes in predator-prey management, predation of huemul fawns and females older than 1 year by native culpeo foxes Lycalopex culpaeus and pumas Puma concolor increased 3- and 5-fold, respectively. Predictions from demographic models suggest that elevated mortality rates of female huemul older than 1 year will, on average, cause this population of huemul to decline. These results highlight risks of unintended consequences when aggressive management actions are taken to protect taxa embedded in complex food webs. They also suggest that careful consideration of both inter- and intra-trophic level effects among all species in a system is warranted before conservation interventions are undertaken.
\end{abstract}

Keywords Food web interactions, guanaco, huemul, Hippocamelus bisulcus, Lama guanicoe, Patagonia National Park, predation, Puma concolor

\footnotetext{
Heiko U. WittmeR* (Corresponding author), School of Biological Sciences, Victoria University of Wellington, New Zealand

E-mail heiko.wittmer@vuw.ac.nz

L. Mark Elbroch Department of Wildlife, Fish, and Conservation Biology, University of California, Davis, USA

ANDREW J. Marshall Department of Anthropology, University of California, Davis, USA

${ }^{\star}$ Also at: Department of Wildlife, Fish, and Conservation Biology, University of California, Davis, USA

Received 4 December 2011. Revision requested 13 February 2012.

Accepted 12 March 2013. First published online 13 May 2013.
}

\section{Introduction}

The establishment of national parks to protect threa1 tened taxa is a cornerstone of modern conservation biology. The designation of protected areas is frequently accompanied by pronounced changes in land use and management. For example, the removal of exotic species (including livestock) is often seen as an essential prerequisite to species conservation within protected areas (Primack, 2010). In addition, the control of native predators is often discouraged because of their important contributions to ecosystem health (e.g. Hebblewhite et al., 2005; Beschta \& Ripple, 2009) and to restore functional predator-prey dynamics among native species.

Our increasing understanding of the role of complex food web interactions in species extinctions, however, suggests that abrupt changes in densities of prey, predators, or both, may not always produce desired conservation outcomes (Sinclair \& Byrom, 2006; Bull \& Courchamp, 2009). For example, because species composition and their relative abundances within communities are at least partially controlled by biotic interactions such as competition and predation (Hairston et al., 1960; Davis, 2003), the abrupt removal of an abundant prey together with stable or increasing predator populations may result in unsustainable mortality rates that potentially jeopardize populations of rare species (Courchamp et al., 2003).

In Chilean Patagonia c. $2,650 \mathrm{~km}^{2}$ of public and private lands are currently being converted into the future Patagonia National Park. A primary objective of the Park is the increased protection of huemul deer Hippocamelus bisulcus (Conservación Patagonica, 2013), Chile's national animal, categorized as Endangered on the IUCN Red List (Jiménez et al., 2008). Huemul are restricted to southern Chile and Argentina (Vila et al., 2006), and the Patagonia National Park will encompass the range of c. $12 \%$ of the estimated 1,00o remaining huemul in Chile (Jiménez et al., 2008). Approximately $30 \%$ of the proposed Park is being contributed through the restoration of one of Chilean Patagonia's largest sheep ranches, the Estancia Vallé Chacabuco (hereafter, the Estancia). In 2004 Conservación Patagonica, the new owners of the Estancia, instituted a number of policies aimed at preparing the ranch for conversion to a national park, including immediate cessation of predator control and the commencement of a 
programme to remove domestic sheep (Conservación Patagonica, 2013).

The historic decline of huemul has generally been attributed to a variety of factors, including habitat loss through conversion of native forest to farmland, overhunting and poaching, and competition with livestock and introduced species (Flueck \& Smith-Flueck, 2006; Jiménez et al., 2008). Recent research, however, suggests that the current population dynamics of huemul in the future Patagonia National Park are primarily affected by predation (Corti et al., 2010). Based on data from marked individuals Corti et al. (2010) reported low survival rates of huemul fawns inside the future Park (females $=0.13 \pm \mathrm{SD} 0.18$; females/males combined $=0.34 \pm$ SD o) with 13 of $16(81 \%)$ known fawn mortalities from predation by culpeo foxes Lycalopex culpaeus $(\mathrm{n}=5)$, domestic dogs $(\mathrm{n}=5)$ and pumas Puma concolor $(\mathrm{n}=3)$, respectively. The authors also reported moderate to high survival rates for adult huemul in the Park (females $=0.94 \pm$ SD 0.07; males $=0.83 \pm \mathrm{SD}$ 0.03), with 6 of $8(75 \%)$ known causes of mortality from predation by pumas $(\mathrm{n}=3)$ and domestic $\operatorname{dogs}(\mathrm{n}=3)$. The prevalence of predation in the Park and the fact that both culpeo foxes and pumas are supported by alternative prey species that are more abundant than huemul across Chilean Patagonia (Novaro et al., 2000) raises concerns about the suitability of the management strategies implemented. In particular, the potential exists for increased mortalities of huemul by expanding predator populations released from local persecution, and simultaneous prey-switching by resident predators that experienced a rapid reduction in an abundant prey (i.e. sheep).

Our objective was to evaluate risks associated with sudden changes in species abundances for threatened species embedded in complex food webs. These changes (i.e. the removal of an abundant prey, sheep, and the concurrent abrupt cessation of predator control) were part of the management associated with the establishment of the Patagonia National Park. Specifically, we hypothesized that huemul survival would be compromised following the reduction in sheep because of increased predation by pumas and culpeo foxes sustained by abundant native guanacos Lama guanicoe and non-native European hares Lepus europaeus. We further hypothesized that reduced huemul survival may result in future population declines of huemul in the proposed Park. Finally, we hypothesized that guanacos would be able to sustain high predation rates by pumas and even increase in abundance, because the removal of sheep, a direct competitor for food and space (Baldi et al., 2004), would result in improved access to suitable valley grasslands from which they were previously excluded.

\section{Study area}

Our study was conducted in Chilean Patagonia (Fig. 1) and encompassed all or parts of three adjacent areas that differed in historic and current land use, topography and vegetation. Firstly, the Estancia is a c. $700 \mathrm{~km}^{2}$ former sheep ranch purchased by Conservación Patagonica in 2004 with the goal of restoring overgrazed grasslands into productive wildlife habitat for native species. The ongoing restoration project included the removal of $>30,000$ sheep and c. $650 \mathrm{~km}$ of fences (Conservación Patagonica, 2011). The Estancia is dominated by steppe grasslands along the c. $90 \mathrm{~km}$ long valley of the Rio Chacabuco. To the north and south of the valley elevation increases markedly and grasslands are gradually replaced by forest-shrublands and forests at higher elevations. Vegetation at mid and

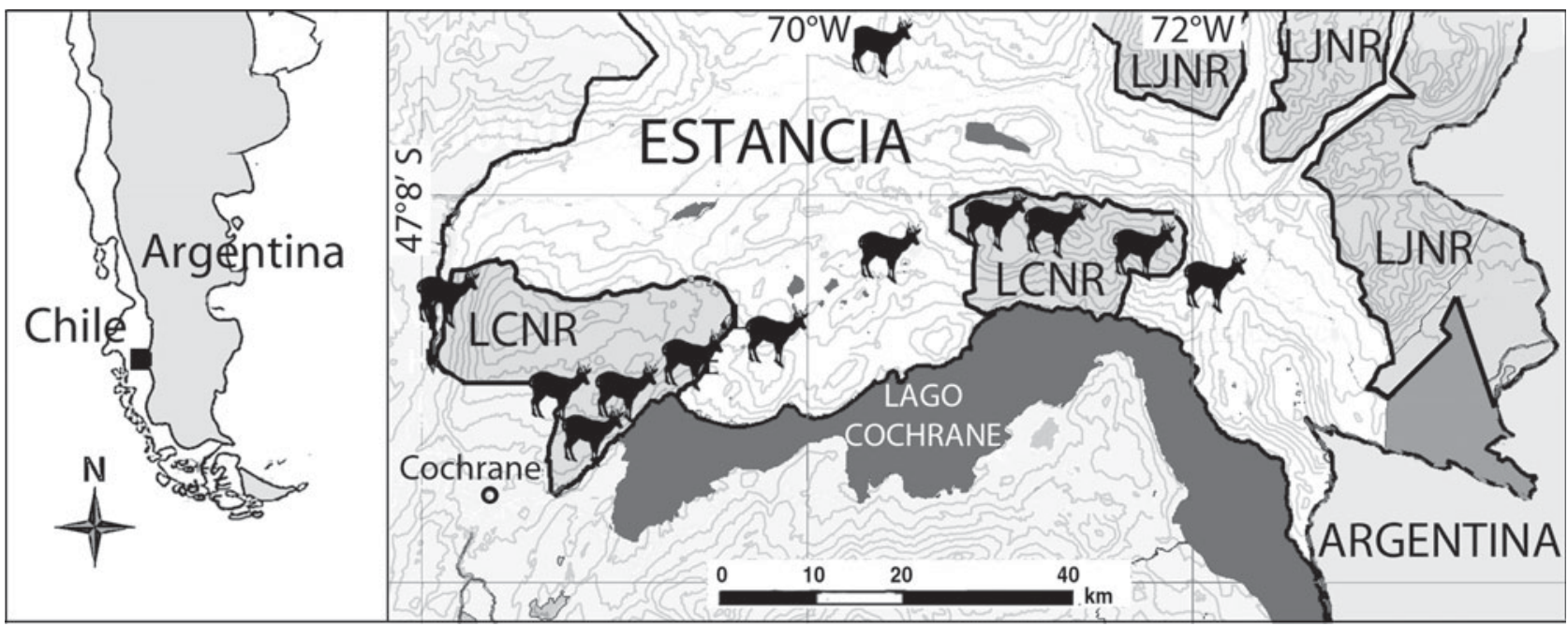

FIG. 1 Location of the study area in Chilean Patagonia and approximate distribution of huemul within the study area, comprising the privately owned Estancia Valle Chacabuco (Estancia), the Lago Cochrane National Reserve (LCNR) and the Lago Jeinimeni National Reserve (LJNR). Each deer symbol represents an estimated 10 individuals. 
higher elevations is dominated by southern beeches Nothofagus spp..

The Estancia is bordered by two designated National Reserves. To the south is the $69 \mathrm{~km}^{2}$ Lago Cochrane National Reserve, established in 1967. The terrain in this Reserve is mostly mountainous with elevations of $150-$ $1,100 \mathrm{~m}$. Forest vegetation in the Reserve is similar to vegetation types found at higher elevations on the Estancia (see Corti et al., 2010, for a more detailed description of vegetation communities in the Reserve). The small town of Cochrane lies c. $4 \mathrm{~km}$ to the west of the Reserve, resulting in moderate human use of a well-developed trail system. North of the Estancia the large Lago Jeinimeni National Reserve encompasses $1,616 \mathrm{~km}^{2}$ of mostly forested habitat over elevations of c. $200 \mathrm{~m}$ to $>2,000 \mathrm{~m}$. Because of its remote location and lack of infrastructure, people rarely use this Reserve. Vegetation is generally dominated by southern beeches. Only the southernmost parts of the Lago Jeinimeni Reserve directly adjacent to the Estancia were included in our study area. The goal of Conservación Patagonica is to combine the Estancia (note that purchases of additional neighbouring properties increased the area contributed to the future Patagonia National Park by Conservación Patagonica to c. $810 \mathrm{~km}^{2}$ ) with the two established Reserves to form the Patagonia National Park, a protected area that will encompass c. $2,650 \mathrm{~km}^{2}$ (Conservación Patagonica, 2013).

Climate varies across our large study area, in part because of topography. In general Patagonian climate is temperate with an annual mean temperature of $6.5^{\circ} \mathrm{C}$ (Endlicher, 1991). Mean annual precipitation in Lago Cochrane National Reserve is $800 \mathrm{~mm}$, the majority of which falls between June and September (Wittmer et al., 2010).

\section{Methods}

\section{Predator-prey system}

Huemul in the study area are part of a diverse mammalian predator-prey system that includes both native and nonnative species (Fig. 2). Domestic sheep are widespread on farms surrounding the study area but have been largely removed from the Estancia (note that c. 2,500 sheep were maintained by Conservación Patagonica and two remaining private landowners in the Chacabuco valley following the period of active sheep removal in 2008; Elbroch \& Wittmer, 2013). Native guanacos are found at varying densities throughout the study area and, being native to steppes, compete with sheep across much of Patagonia (Baldi et al., 2004). European hares were introduced in the early 1900 s and are widespread across Patagonia (Grigera \& Rapoport, 1983), including our study area. Pumas and culpeo foxes, the only large, native predators in Patagonia, both prey on huemul (Corti et al., 2010).

\section{Data collection and analyses}

Sheep When Conservación Patagonica purchased the Estancia in 2004 the ranch contained c. 30,000 sheep (Conservación Patagonica, 2013). Sheep were removed from the Estancia over 4 years (Conservación Patagonica, 2013), with most stock sold off prior to August 2007 (H. Wittmer, pers. obs.). Prior to being sold off, sheep mostly occupied valley steppe habitat. Our data on the number of sheep lost to predation are limited to personal observations during visits in 2007 and 2008 or based on kills made by pumas fitted with Argos global positioning system (GPS) collars (see below). Sheep were absent from the adjacent Lago Cochrane and Lago Jeinimeni National Reserves.

Guanacos Abundances of guanacos varied among habitat types and were highest in the steppe habitats on the Estancia (Elbroch \& Wittmer, 2012). Following sheep and fence removals, guanaco numbers are believed to have increased, with Conservación Patagonica reporting a total population size of $>2,500$ (Conservación Patagonica, 2013) prior to 2010. Because this estimate was based on counts covering only parts of the Estancia (H. Wittmer, pers. obs.), we treated it as an estimate of the minimum number of guanacos on the Estancia following sheep removal.

In September 2010 we estimated the total number of guanacos on the Estancia using distance sampling (Elbroch \& Wittmer, 2012). Two observers walked 60 predetermined $1-\mathrm{km}$ transects evenly distributed across the three major

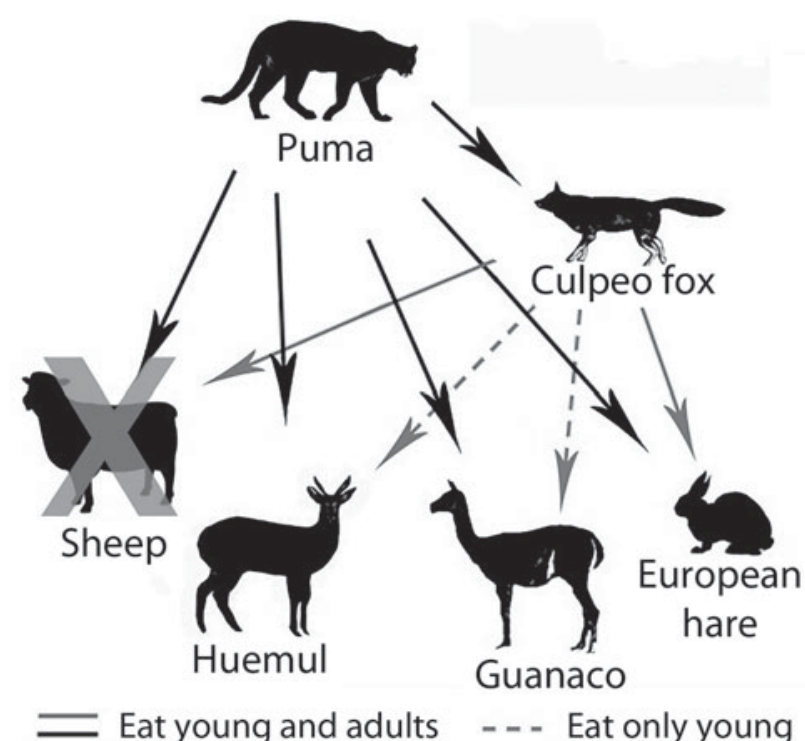

FIG. 2 Simplified predator-prey system and food web interactions in the study area in Chilean Patagonia (Fig. 1) before and after sheep removal. Solid arrows indicate predation of all age classes of prey and dashed arrows indicate predation of young individuals only. 
habitat types (valley steppe, where observers sampled up to $400 \mathrm{~m}$ on either side of transects; mountain steppe, where up to $100 \mathrm{~m}$ on either side of transects was sampled; and shrub-woodland/forest). We estimated perpendicular distances from the centre of guanaco groups using angles measured with compasses and distances measured with laser rangefinders. We then used Distance v. 6.o (Thomas et al., 2010) to estimate the total number of guanacos on the Estancia, adjusted for general habitat types. The number of resident guanacos in the surrounding National Reserves was negligible, totalling c. 50 individuals (Torres, 1992). These low densities were probably because most of the Reserves comprised forests, habitat that guanacos rarely inhabit.

European hares Hares were seen frequently across the entire study area but their abundance on the Estancia was only estimated in 2010, based on $80 \mathrm{~km}$ of spotlight counts on roads (Elbroch \& Wittmer, 2012). The amount of roads within steppe (combined valley and mountain steppes) and shrub-woodland/forest habitats was determined retrospectively and habitat-specific hare densities were then estimated using Distance v. 6.o (Thomas et al., 2010). Hares were also commonly seen in the adjacent National Reserves where we did not attempt to estimate their abundances.

Culpeo foxes Culpeo foxes are a significant predator of huemul fawns (Corti et al., 2010). Despite their apparent impact on fawns, no formal attempts were undertaken to estimate their abundances in the study area. However, culpeo foxes were frequently seen across the study area and it is likely that their densities have increased following the acquisition of the Estancia by Conservación Patagonica in 2004.

Pumas We successfully captured nine pumas (five females, four males) between April 2008 and August 2009 (Table 1) and fitted them with Argos GPS collars. Capture procedures were described in Elbroch et al. (2010). We programmed collars to collect location data at 2-hour intervals, with data downloaded via the internet at 2-4 day intervals. We investigated all GPS location clusters where a puma remained for $\geqslant 2$ hours between dusk and dawn within $11 \pm$ SD 12 days of data acquisition, excepting those that had to be investigated retrospectively after GPS location data were downloaded from one collar that had the Argos uplink fail (Elbroch \& Wittmer, 2013). This method allowed us to (1) determine reliably the contribution of large mammalian prey to the diet of pumas, (2) ascertain whether an individual puma overlapped with known distributions of huemul in the study area, and (3) detect rapidly any huemul killed by collared pumas. Prior to the change in ownership in 2004, pumas detected on the Estancia were killed illegally but, as with culpeo foxes, pumas were no longer killed once the Estancia changed ownership (Conservación Patagonica, 2013). In 2009 we estimated puma densities as 1.35 resident adults per $100 \mathrm{~km}^{2}$ or 3.44 total pumas per $100 \mathrm{~km}^{2}$ including known kittens (Elbroch \& Wittmer, 2012).

Huemul There were c. 120 huemul in our study area (Corti, 2008), fragmented into either family groups or distinct populations (Fig. 1). The huemul population in a $19 \mathrm{~km}^{2}$ section of the Lago Cochrane National Reserve has been monitored since 1991 and intensively studied using marked individuals from 2005 to 2008. Marking procedures included fitting 18 fawns and 19 animals older than 1 year with VHF transmitters, and identifying an additional 21 fawns and 30 animals older than 1 year through ear tags, natural markings, or association with tagged individuals (see Corti et al., 2010, for a detailed description of marking procedures). Because of the large sample of marked individuals huemul abundances in the Reserve were well known. Population estimates outside Lago Cochrane Reserve were largely based on periodic surveys in which wardens reported individuals they encountered, and were therefore less accurate (Wittmer et al., 2010).

Based on the sample of marked individuals Corti et al. (2010) calculated age-specific survival rates for huemul

TABLE 1 Monitoring dates of nine pumas fitted with Argos GPS collars in the Patagonia National Park between April 2008 and November 2010, including the number of huemul within estimated puma home ranges (Elbroch \& Wittmer, 2012) and number of huemul kills.

\begin{tabular}{llllll}
\hline & $\begin{array}{l}\text { Start of } \\
\text { Puma }\end{array}$ & $\begin{array}{l}\text { End of } \\
\text { monitoring }\end{array}$ & $\begin{array}{l}\text { Duration of } \\
\text { monitoring } \\
\text { (days) }\end{array}$ & $\begin{array}{l}\text { Overlap with huemul } \\
\text { (no. of huemul }>\text { 1 year old) }\end{array}$ & No. of huemul kills found \\
\hline F1 & 4 Apr. 2008 & 1 Nov. 2008 & 211 & no & \\
M1* & 12 Apr. 2008 & 21 July 2008 & 110 & no & 0 \\
F2 & 24 July 2008 & 23 Oct. 2008 & 91 & yes (26) & 2 (adult females) \\
M2 & 29 May 2009 & 25 Aug. 2010 & 453 & yes (70) & (2 fawns, 2 yearlings, 1 adult male) \\
F4 & 1 June 2009 & 28 Aug. 2010 & 453 & yes (44) & 0 \\
F3 & 3 June 2009 & 19 Nov. 2010 & 534 & no & 0 \\
$\mathrm{M} 3$ & 24 June 2009 & 10 June 2010 & 351 & yes (9) & 0 \\
$\mathrm{M} 4$ & 26 June 2009 & 26 Feb. 2010 & 245 & yes (22) & \\
F5 & 23 Aug. 2009 & 17 Apr. 2010 & 237 & yes (26) &
\end{tabular}

${ }^{*}$ Dispersed from the study area and confirmed killed on an Argentinian sheep ranch (Elbroch et al., 2009) 
between April 2005 and June 2008 using Kaplan-Meier procedures (Pollock et al., 1989). Here we use new data to: update age-specific survival estimates of huemul older than 1 year based on two different scenarios (see below), provide updated estimates of fawn survival and causes of mortality, and project population growth rates of huemul in the proposed Patagonia National Park following changes in management.

Huemul survival rates of females older than 1 year provided by Corti et al. (2010; Table 2) were modified to account for both the observed predation of huemul by collared pumas as well as mortalities of marked huemul attributed to puma predation since the previous study ended in June 2008. We updated survival estimates using two equations:

$$
\begin{gathered}
S_{\text {compensatory }}=S_{0}-M_{0} \cdot P_{p} / 100 \cdot r_{p}+M_{0} \\
S_{\text {additive }}=S_{0}-M_{0} \cdot P_{p} / 100 \cdot r_{p}+M_{0} \cdot P_{p} / 100
\end{gathered}
$$

where $S_{0}$ is the age-specific survival rate of female huemul reported in Corti et al. (2010), $M_{0}$ the initial age-specific mortality rate (i.e. $1-S_{0}$ ), $P_{p}$ the initial percentage of mortality from puma predation (note that only one of the three huemul preyed upon by pumas between April 2005 and June 2008 was female (Corti et al., 2010); we thus also calculated the percentage of puma predation for both sexes pooled to avoid problems associated with small sample sizes), and $r_{p}$ the proportional increase in mortalities per month per huemul (a) from observed huemul kills of collared pumas between April 2008 and November 2010 adjusted for the estimated number of female huemul $>_{1}$ year old within home ranges of individual pumas (Table 1; Elbroch \& Wittmer, 2012), and (b) using mortality information of marked huemul in Lago Cochrane National Reserve for the period between July 2008 and August 2009 when such data were available. In Equation (1) we assumed that mortality from pumas observed in this study was compensatory whereas in Equation (2) we assumed that mortality from pumas was additive to causes of mortality previously reported.
We updated estimates of fawn survival probabilities from Corti et al. (2010), based on 2 years of data only, using new data collected between June 2008 and September 2009 from 16 fawns fitted with either VHF ear tags $(n=14)$ or identified through association with known individuals $(n=2)$. We also updated the causes of mortalities but, contrary to Corti et al. (2010), limited our analysis to fawns marked with VHF ear tags to avoid problems associated with differences in the detection probability of dead fawns with and without VHF ear tags.

We adjusted a matrix model used by Corti et al. (2010) to estimate the projected population growth rate $(\lambda)$ of huemul in the future Patagonia National Park following the removal of sheep and the cessation of predator control. To account for uncertainties in estimates of vital rates we sampled both fertility and age-specific survival 1,00o times. Reported 95\% confidence limits of estimated $\lambda$ were based on the percentile method (Efron \& Tibshirani, 1993).

\section{Biomass estimates}

Estimates of prey abundances (sheep, guanacos, European hares and huemul) in 2010 were converted into biomass ( $\mathrm{kg}$ of meat) to reflect better their potential energetic contributions to the diet of predators (Elbroch \& Wittmer, 2012).

\section{Results}

\section{Sheep}

The number of sheep on the Estancia was actively reduced from $>25,000$ in 2005 to $<2,000$ by 2008 . Throughout a 4-year removal period $>30,000$ sheep were sold off (Conservación Patagonica, 2013). Sheep appeared to provide substantial amounts of food for predators during and after the removal project. For example, during visits in August 2007 and July 2008, sheep killed by culpeo foxes or pumas were found daily (H. Wittmer, pers. obs.). In 2010 sheep still comprised $2.3 \%$ of the available prey biomass in the study area.

TABLE 2 Estimates of age-specific vital rates \pm SD of female huemul and $\lambda$ (95\% confidence intervals) as presented in Corti et al. (2010) and updated results based on (1) 2 additional years of monitoring survival of marked fawns, (2) observed mortalities of marked huemul $>1$ year old between July 2008 and August 2009, and (3) increases in observed huemul kill rates by marked pumas in the Patagonia National Park between April 2008 and November 2010. Observed increases in mortalities of huemul $>1$ year old were either considered compensatory or additive to those reported by Corti et al. (2010).

\begin{tabular}{llll}
\hline & $\begin{array}{l}\text { Corti et al. (2010), } \\
\text { data until 2008 }\end{array}$ & $\begin{array}{l}\text { Compensatory } \\
\text { mortality scenario }\end{array}$ & $\begin{array}{l}\text { Additive mortality } \\
\text { scenario }\end{array}$ \\
\hline Fawn survival (0-1 years) & $0.13 \pm 0.18$ & $0.18 \pm 0.11$ & $0.18 \pm 0.11$ \\
Yearling survival (1-2 years) & $0.88 \pm 0.13$ & $0.78 \pm 0.13$ & $0.70 \pm 0.13$ \\
Juvenile survival (2-3 years) & $0.91 \pm 0.16$ & $0.84 \pm 0.16$ & $0.78 \pm 0.16$ \\
Adult survival (>3 years) & $0.94 \pm 0.07$ & $0.89 \pm 0.07$ & $0.85 \pm 0.07$ \\
Fertility & $0.72 \pm 0.20$ & $0.72 \pm 0.20$ & $0.72 \pm 0.20$ \\
$\lambda(95 \% \mathrm{CI})$ & $1.01(0.84-1.17)$ & $0.97(0.83-1.11)$ & $0.93(0.78-1.07)$ \\
\hline
\end{tabular}




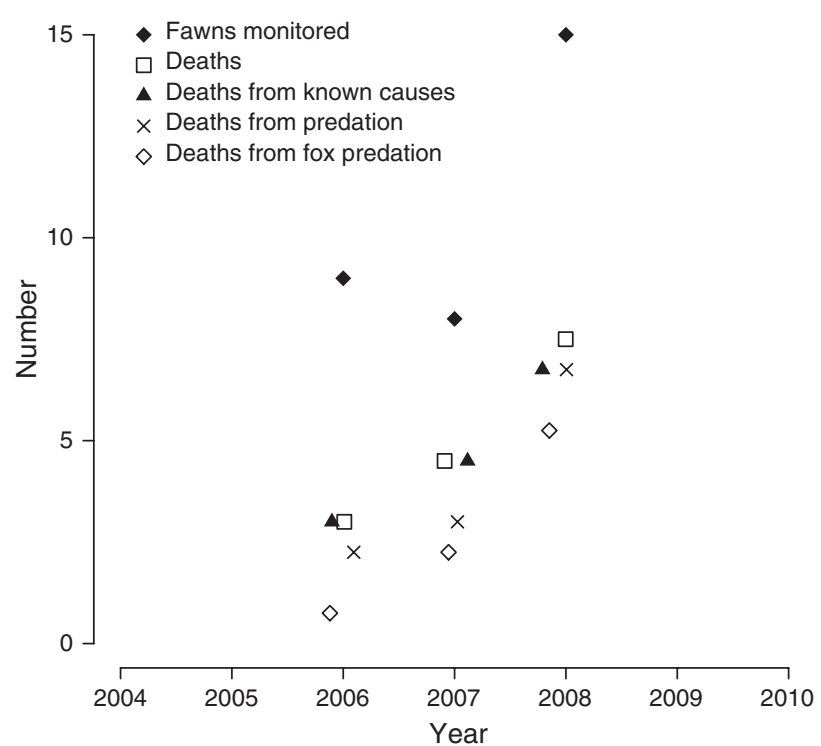

FIG. 3 Causes of mortality of huemul fawns fitted with VHF eartag transmitters in Chilean Patagonia between April 2005 and September 2009 (modified and updated from Corti et al., 2010).

\section{Guanacos}

The number of guanacos recovered to $>2,500$ individuals post-sheep removal (Conservación Patagonica, 2013) and as early as 2008 guanacos were the most abundant large mammalian prey species on the Estancia (H. Wittmer \& M. Elbroch, pers. obs). The more accurate population estimate in 2010 revealed a total population size of c. 6,550 (95\% CI 3,316-17,629) guanacos over our 1,062 $\mathrm{km}^{2}$ sampling area. Densities were highest in valley steppe habitat (69.1 km ${ }^{-2}$, 95\% CI 34.9-149.6) followed by mountain steppe habitat (30.4 km $\left.{ }^{-2}, 95 \% \mathrm{CI} 15.4-86.1\right)$. These numbers reflect only steppe habitat in which guanacos were found. There remained c. $153 \mathrm{~km}^{2}$ of steppe habitat from which guanacos were excluded by ranchers and the presence of remaining sheep. Guanacos were not detected along transects in shrub-woodland or forested habitats. Although data available do not allow an estimation of population trends, our personal observations are in agreement with an assessment from Conservación Patagonica (2013) that guanaco have probably increased in the study area following the removal of sheep. In 2010 guanacos comprised $88.6 \%$ of the available prey biomass in the study area.

\section{European hares}

Hare densities on the Estancia in winter 2010 averaged 42.5 $\mathrm{km}^{-2}$ (95\% CI 20.3-89.3) in steppe habitat (pooled across valley and mountain steppe) and $89.0 \mathrm{~km}^{-2}$ (95\% CI $44.3^{-}$ 179.1) in shrub-woodland habitats. These estimates translate into a total winter population of 21,973 hares ( $95 \%$ CI 13,078$45,916)$ over the $1,062 \mathrm{~km}^{2}$ sampling area. In 2010 hares comprised $8.5 \%$ of the available prey biomass in the study area.

\section{Culpeo foxes}

Predation of huemul fawns attributed to foxes increased 3 -fold from $25 \%$ of known causes of mortalities for the 2006 cohort to $78 \%$ for the 2008 cohort (Fig. 3). Culpeo foxes probably killed a much higher number and biomass of sheep based on our limited personal observations during the same time period.

\section{Pumas}

We found 350 kill sites of collared pumas with remains of guanacos, sheep and huemul (Elbroch \& Wittmer, 2013). The majority of these were guanacos $(\mathrm{n}=302)$ and sheep $(n=41)$. Based on their respective availabilities in terms of biomass, all three ungulate prey species contributed as or more than expected to the diet of pumas. Overall, huemul contributed $0.9 \%$ of the diet of collared pumas, nearly two times higher than expected based upon their available biomass of $0.5 \%$. It is likely that pumas killed a much higher number and biomass of sheep during the period of sheep removal ( $\mathrm{H}$. Wittmer, pers. obs.).

Puma kill rates of huemul during our study were higher than previously reported. Only three marked huemul $>_{1}$ year of age (one female, two males) out of a population of c. 39 huemul (23 females, 16 males) were killed by pumas over a 39 month period between April 2005 and June 2008 (females $=0.0011$ mortalities per month per female huemul; pooled $=0.0020$ mortalities per month per huemul; Corti et al., 2010). Over the following 14 months between July 2008 and August 2009 three marked huemul $>_{1}$ year of age (two females, one male) were killed by pumas, indicating a 5.63-fold increase in predation for marked females (0.0062 mortalities per month per female huemul) or 2.75 -fold increase overall (0.0055 mortalities per month per female huemul).

Only six of the nine collared pumas we monitored between April 2008 and November 2010 overlapped with the known distribution of huemul in our study area (Table 1). Two of these pumas, $\mathrm{M}_{2}$ and $\mathrm{F}_{4}$, killed at least five huemul (three females, two males) $>1$ year of age as well as two fawns over a monitoring period of 14.9 months each. Home ranges of these two collared pumas overlapped completely with each other and provided access to a combined 80 of the 120 huemul in the study area (Elbroch \& Wittmer, 2012), 35 of which we assumed to be females $>_{1}$ year of age (70 males and females combined). Adjusted monthly kill rates (females $=0.0058$ mortalities per month per female huemul; pooled $=0.0096$ mortalities per month per huemul) indicated 5.27 times higher puma predation 
rates for females and 4.79 higher overall predation rates than previously reported. When combining the two data sets (mortalities of collared huemul attributable to puma predation and huemul kills by collared pumas), we estimated that predation of female huemul had increased 5.45 ( \pm SD 0.25 ) fold and puma predation overall increased 3.77 ( \pm SD 1.44) fold.

\section{Huemul}

Kill rates from pumas (see above) suggest a 5.45-fold increase in puma predation of female huemul $>1$ year of age compared to the findings of Corti et al. (2010). Increased kill rates resulted in drastically reduced age-specific survival estimates of female huemul in our study area under both the compensatory and additive scenarios (Table 2). Despite significant uncertainty, estimates of $\lambda$ on average project a decline in the huemul population in the future Patagonia National Park under both scenarios (Table 2). Under the compensatory scenario $62 \%$ of estimates of $\lambda$ were indicative of a declining population, and under the additive mortality scenario $82 \%$ of estimates of $\lambda$ projected a population decline.

Survival rates of female huemul fawns from 2005 until 2009 averaged $0.18 \pm$ SD 0.11. Twenty of all 32 huemul fawns fitted with VHF ear-tag transmitters died during their first year of life. Eighty-four percent of the known causes of fawn mortality (16 out of 19 fawns with VHF ear-tag transmitters) were attributable to predation, with predation from foxes being the most significant cause of mortality (Fig. 3). Both the number of huemul fawns killed by predators as well as fawns killed by culpeo foxes increased over time (Fig. 3).

\section{Discussion}

Our results indicate that the well-intentioned decision to reduce abruptly the number of domestic sheep and simultaneously halt predator control in preparation for transforming the Estancia into a national park has resulted in unintended negative consequences for the small population of huemul. Although we were unable to tease apart the relative contributions of sheep reductions from the effects of the decision to stop predator control, our models suggest that based on current estimates of vital rates huemul in the area are, on average, expected to decline in the future Patagonia National Park. Results from our study highlight the potential risks associated with sudden changes in relative species abundances for threatened species embedded in complex food webs, and provide support for previous warnings urging managers to consider carefully the potential unintended consequences of their decisions prior to conservation actions (e.g. Bull \& Courchamp, 2009).
The most dramatic consequence attributable to changes in predator-prey management in the future Patagonia National Park was the increase in predation of female huemul $>_{1}$ year old by pumas. Increased puma predation rates may be driven by increased puma abundances following the cessation of predator control in the Park. Current density estimates for pumas in the Park are comparable to densities reported from unhunted populations in North America where pumas rely on large ungulate prey (Quigley \& Hornocker, 2010) but were more than four times higher than densities of pumas in South America that primarily persist on small mammalian prey (Kelly et al., 2008). The hypothesis that puma densities in the future Patagonia National Park have increased dramatically was also supported by anecdotal evidence collected from park wardens, who reported increased puma sightings and encounters with puma tracks since the change in ranch ownership in 2004. Given the significant contribution of locally abundant guanacos to the diet of pumas in our study area (Elbroch \& Wittmer, 2013), it is likely that puma densities will remain high for the foreseeable future.

Although increased mortality rates of huemul could have been the result of increased puma densities, an alternative explanation is that they were because of specialization on huemul by a few individual pumas. Our results do not suggest that increased huemul mortalities were caused by prey switching of resident pumas on the Estancia; rather, they are consistent with prey selection by newly established pumas that arrived when prey assemblages changed following the sheep reductions. Although only two of the six collared pumas overlapping with the distribution of huemul were observed to kill huemul, this observed specialization was sufficient to reduce huemul survival to a point at which models project a potential population decline. It is notable that specialist behaviour and stochastic predation by pumas has been previously reported to contribute to the decline of bighorn sheep Ovis canadensis in Canada (Ross et al., 1997; Festa-Bianchet et al., 2006). For example, Ross et al. (1997) reported that one female puma killed $8.7 \%$ of a local bighorn sheep population during one winter.

We also demonstrated a 3 -fold increase in mortalities of huemul fawns attributed to culpeo foxes during and following changes in predator-prey management on the Estancia. However, although mortality from foxes increased over time, survival rates of female huemul fawns based on 4 years of data reported here were actually higher than estimates based on 2 years of data previously reported by Corti et al. (2010). Thus, it is unlikely that increased fox predation is the direct cause of the population declines projected by our model. Instead, increased fox predation prevents recruitment being sufficient to offset increased adult mortalities from puma predation. This observation is consistent with our current understanding of ungulate population dynamics, which predicts that long-lived, 
iteroparous species such as huemul are well adapted to high variability in juvenile survival (Gaillard et al., 2000) but that concurrent reductions in adult female survival usually result in precipitous population declines (Johnson et al., 2010).

Our results differ in three important ways from results previously reported by Corti et al. (2010). Firstly, our results indicate lower survival of huemul $>_{1}$ year old in the Patagonia National Park. We suggest that the very small spatial scale (i.e. $19 \mathrm{~km}^{2}$ ) of the telemetry study conducted by Corti et al. (2010) prevented them from obtaining survival estimates representative of huemul in the much larger Patagonia National Park. For example, based on results of our puma study conducted across most of the distribution of huemul in the Park only one collared puma, a 5-year old male, was known to overlap with the distribution of marked huemul in Lago Cochrane National Reserve (Elbroch \& Wittmer, 2012). This individual, however, was known to preferentially kill guanacos and thus mostly killed prey in open grassland habitats avoided by huemul (Elbroch \& Wittmer, 2013). Secondly, our updated matrix model based on the observed lower survival of females predicts that, on average, the huemul population in Patagonia National Park is expected to decline rather than remain stable as suggested by Corti et al. (2010). Although it is unlikely that predation from pumas is completely additive (e.g. bone marrow of two adults killed by puma M2 indicated poor health; Elbroch \& Wittmer, 2013) it is important to highlight that some pumas overlapping with huemul were monitored for short periods of time and not all pumas in our study area were monitored, suggesting that puma predation rates may be higher than we reported. Thirdly, when we limited the analysis of causes of fawn mortalities to animals with VHF ear tags we found that predation by foxes rather than domestic dogs appears to be the limiting factor for huemul fawns in the Park. The fact that the mortalities attributed to dogs in Corti et al. (2010) were animals without VHF tags that were opportunistically observed because they occurred close to the township of Cochrane, may have potentially biased previous results. We do not suggest that predation by dogs was insignificant but available data are insufficient to quantify the impact of dog predation on huemul in the Park.

Our results, however, also indicate that native guanacos may be rapidly benefiting from the reduction of sheep and increased access to high quality grassland habitats, confirming results from a previous study in Argentine Patagonia (Burgi et al., 2012). It is notable that guanacos in our study area appear to be increasing despite significant predation from pumas (Elbroch \& Wittmer, 2013). Although this is good news for a species considered conservation dependent (Baldi et al., 2008) we are concerned that the increase in guanacos could support high densities of native predators and create 'apparent competition' (Holt, 1977) scenarios between guanacos and huemul. Apparent competition has increasingly been linked to the decline of threatened ungulates (DeCesare et al., 2010). Intensive monitoring of huemul based on marked animals is thus required to determine rates of population change accurately across their entire distribution in Patagonia National Park (Wittmer et al., 2010). Additionally, targeted removal of pumas known to kill huemul should be considered, to counteract increased mortalities of huemul at risk from apparent competition (Wittmer et al., 2013).

Conserving threatened species embedded in complex food webs poses significant challenges for managers because simply protecting sufficient suitable habitat does not necessarily address the underlying cause of decline, namely the linked dynamics of all species within their ecological community (Sinclair \& Byrom, 2006). Because communities are based on the interaction of their constituent species and their physical environment (Begon et al., 2006) any alteration to the species composition can also alter interactions between species (Chapin et al., 2000). Thus, prior to manipulating the relative abundance of species, particularly those of abundant prey species that share predators with rare and threatened prey species, the potential negative consequences should be considered (for example via modelling population dynamics under different management scenarios; Courchamp et al., 2003). Risks associated with changing the composition of communities are probably greatest in systems with well-established species interactions and a large number of interacting species (Zavaleta et al., 2001), where invasive/exotic species create new or altered competition/predation scenarios (Courchamp et al., 1999) and where native predators are increasing following cessation of persecution by humans (Lovari et al., 2009). In the context of biological invasions studies examining the effect of the eradication of single species have documented unintended, detrimental impacts on native species for which the original intent was their conservation (Bull \& Courchamp, 2009). Our results similarly highlight the importance of considering how food web interactions (both inter- and intra-trophic levels) may affect all other species in a community prior to implementing management aimed at changing relative abundances.

\section{Acknowledgements}

This study was funded by the following organizations: National Geographic Society (Grant No. C131-07 to HUW), National Science Foundation, Conservación Patagonica, Felidae Conservation Fund, American Society of Mammalogists, the Hemispheric Institute of the Americas, Oregon Zoo, and the Pacific Rim Research Program. All capture procedures were approved by an independent Institutional Animal Care and Use Committee at the University of California, Davis (Protocol No. 13252) as well 
as the Natural Renewable Resources Division of the Agricultural Service of Chile. We appreciate the contributions of multiple individuals to fieldwork and helpful discussions with P. Corti and C. Saucedo at the beginning of this project. R. Serrouya, M. Hasenbank and two anonymous reviewers provided many helpful comments.

\section{References}

Baldi, B., Lichtenstein, G., González, B., Funes, M., Cuéllar, E., Villalba, L. et al. (2008) Lama guanicoe. In IUCN Red List of Threatened Species v. 2012.1. Http://www.iucnredlist.org [accessed 16 October 2012].

Baldi, R., Pelliza-Sbriller, A., Elston, D. \& Albon, S. (2004) High potential for competition between guanacos and sheep in Patagonia. Journal of Wildlife Management, 68, 924-938.

Begon, M., Townsend, C.R. \& Harper, J.L. (2006) Ecology: From Individuals to Ecosystems, 4th edition. Blackwell Publishing, Malden, USA.

Beschta, R.L. \& Ripple, W.J. (2009) Large predators and trophic cascades in terrestrial ecosystems of the western United States. Biological Conservation, 142, 2401-2404.

Bull, L.S. \& CourChamp, F. (2009) Management of interacting invasives: ecosystem approaches. In Invasive Species Management: A Handbook of Principles and Techniques (eds M.N. Clout \& P.A. Williams), pp. 232-247. Oxford University Press, Oxford, UK.

Burgi, M.V., Marino, A., Rodriguez, M.V., Pazos, G. \& Baldi, R. (2012) Response of guanacos Lama guanicoe to changes in land management in Peninsula Valdés, Argentine Patagonia: conservation implications. Oryx, 46, 99-105.

Chapin, F.S., Zavaleta, E.S., Eviner, V.T., Naylor, R.L., Vitousek, P.M., Reynolds, H.L. et al. (2000) Consequences of changing biodiversity. Nature, 405, 234-242.

Conservación Patagonica (2011) Http://www. conservacionpatagonica.org/ [accessed 1 December 2011].

Conservación Patagonica (2013) Http://www. conservacionpatagonica.org/ [accessed 8 March 2013].

Corti, P. (2008) Organisation sociale, dynamique de population, et conservation du cerf huemul (Hippocamelus bisulcus) dans la Patagonie du Chili. PhD thesis. Department of Biology, University of Sherbrooke, Sherbrooke, Canada.

Corti, P., Wittmer, H.U. \& Festa-Bianchet, M. (2010) Dynamics of a small population of endangered huemul deer (Hippocamelus bisulcus) in Chilean Patagonia. Journal of Mammalogy, 91, 690-697.

Courchamp, F., Langlais, M. \& Sugihara, G. (1999) Cats protecting birds: modelling the mesopredator release effect. Journal of Animal Ecology, 68, 282-292.

Courchamp, F., Woodroffe, R. \& Roemer, G. (2003) Removing protected populations to save endangered species. Science, 302, 1532.

DAvis, M.A. (2003) Biotic globalization: does competition from introduced species threaten biodiversity? BioScience, 53, 481-489.

DeCesare, N.J., Hebblewhite, M., Robinson, H.S. \& Musiani, M. (2010) Endangered apparently: the role of apparent competition in endangered species conservation. Animal Conservation, 13, 353-362.

Efron, B. \& Tibshirani, R. (1993) An Introduction to the Bootstrap. Chapman and Hall, New York, USA.

Elbroch, L.M., Saucedo, C. \& Wittmer, H.U. (2010) Swimming by pumas (Puma concolor) in Patagonia: rethinking barriers to puma movement. Studies on Neotropical Fauna and Environment, 45, 187-190.

Elbroch, L.M. \& Wittmer, H.U. (2012) Puma spatial ecology in open habitats with aggregate prey. Mammalian Biology, 77, 377-384.
Elbroch, L.M. \& Wittmer, H.U. (2013) The effects of puma prey selection and specialization on less abundant prey in Patagonia. Journal of Mammalogy, 94, 259-268.

Elbroch, L.M., Wittmer, H.U., Saucedo, C. \& Corti, P. (2009) Long-distance dispersal of a male puma (Puma concolor puma) in Patagonia. Revista Chilena de Historia Natural, 82, 459-461.

Endlicher, W. (1991) Zur Klimageographie und Klimaökologie von Südpatagonien. 10o Jahre klimatologische Messungen in Punta Arenas. Freiburger Geographische Hefte, 32, 181-211.

Festa-Bianchet, M., Coulson, T., Gaillard, J.-M., Hogg, J.T. \& Pelletier, F. (2006) Stochastic predation events and population persistence in bighorn sheep. Proceedings of the Royal Society B, 273, 1537-1543.

Flueck, W.T. \& Smith-Flueck, J.M. (2006) Predicaments of endangered huemul deer, Hippocamelus bisulcus, in Argentina: a review. European Journal of Wildlife Research, 52, 69-80.

Gaillard, J.-M., Festa-Bianchet, M., Yoccoz, N.G., Loison, A. \& Tolgo, C. (2000) Temporal variation in fitness components and population dynamics of large herbivores. Annual Reviews in Ecology, Evolution and Systematics, 31, 367-393.

Grigera, D.E. \& RApoport, E.H. (1983) Status and distribution of the European hare in South America. Journal of Mammalogy, 64, $163-166$.

Hairston, N.G., Smith, F.E. \& Slobodkin, L.B. (1960) Community structure, population control, and competition. American Naturalist, 94, 421-425.

Hebblewhite, M., White, C.A., Nietvelt, C.G., McKenzie, J.A., Hurd, T.E., Fryxell, J.M. et al. (2005) Human activity mediates a trophic cascade caused by wolves. Ecology, 86, 2135-2144.

Holt, R.D. (1977) Predation, apparent competition, and the structure of prey communities. Theoretical Population Biology, 12, 197-229.

Jiménez, J., Guineo, G., Corti, P., Smith, J.A., Flueck, W., Vila, A. et al. (2008) Hippocamelus bisulcus. In IUCN Red List of Threatened Species v. 2012.1. Http://www.iucnredlist.org [accessed 16 October 2012].

Johnson, H.E., Mills, L.S., Stephenson, T.R. \& Wehausen, J.D. (2010) Population-specific vital rate contributions influence management of an endangered ungulate. Ecological Applications, 20, 1753-1765.

Kelly, M.J., Noss, A.J., Di Bitetti, M.S., Maffei, L., Arispe, R.L., Paviolo, A. et al. (2008) Estimating puma densities from camera trapping across three study sites: Bolivia, Argentina, and Belize. Journal of Mammalogy, 89, 408-418.

Lovari, S., Boesi, R., Minder, I., Mucci, N., Randi, E., Dematteis, A. \& Ale, S.B. (2009) Restoring a keystone predator may endanger a prey species in a human altered ecosystem: the return of the snow leopard to Sagarmatha National Park. Animal Conservation, 12, 559-570.

Novaro, A.J., Funes, M.C. \& Walker, R.S. (2000) Ecological extinction of native prey of a carnivore assemblage in Argentine Patagonia. Biological Conservation, 92, 25-33.

Pollock, K.H., Winterstein, S.R., Bunck, C.M. \& Curtis, P.D. (1989) Survival analysis in telemetry studies: the staggered entry design. Journal of Wildlife Management, 53, 7-15.

Primack, R.B. (2010) Essentials of Conservation Biology, 5 th edition. Sinauer Associates, Sunderland, USA.

Quigley, H. \& Hornocker, M. (2010) Cougar population dynamics. In Cougar: Ecology and Conservation (eds M. Hornocker \& S. Negri), pp. 59-75. University of Chicago Press, Chicago, USA.

Ross, P.I., Jalkotzy, M.G. \& Festa-Bianchet, M. (1997) Cougar predation on bighorn sheep in southwestern Alberta during winter. Canadian Journal of Zoology, 75, 771-775.

Sinclair, A.R.E. \& Byrom, A.E. (2006) Understanding ecosystem dynamics for conservation of biota. Journal of Animal Ecology, 75, 64-79. 
Thomas, L., Buckland, S.T., Rexstad, E.A., Laake, J.L., StrindberG, S., Hedley, S.L. et al. (2010) Distance software: design and analysis of distance sampling surveys for estimating population size. Journal of Applied Ecology, 47, 5-14.

Torres, H. (1992) South American Camelids: An Action Plan for their Conservation. IUCN, Gland, Switzerland.

Vila, A.R., López, R., Pastore, H., Faúndez, R. \& Serret, A. (2006) Current distribution and conservation of the huemul (Hippocamelus bisulcus) in Argentina and Chile. Mastozoologia Neotropical, 13, 263-269.

Wittmer, H.U., Corti, P., Saucedo, C. \& Galaz, J.L. (2010) Learning to count: adapting population monitoring for Endangered huemul deer Hippocamelus bisulcus to meet conservation objectives. Oryx, 44, 516-522.

Wittmer, H.U., Serrouya, R., Elbroch, L.M. \& Marshall, A.J. (2013) Conservation strategies for species affected by apparent competition. Conservation Biology, 27, 254-260.
Zavaleta, E.S., Hobbs, R.J. \& Mooney, H.A. (2001) Viewing invasive species removal in a whole-ecosystem context. Trends in Ecology \& Evolution, 16, 454-459.

\section{Biographical sketches}

Heiko U. Wittmer's research focuses on the dynamical consequences of predation for threatened ungulates in multi-prey, multipredator systems. He is also a member of the IUCN deer specialist group. L. MARK ELBRoch is interested in carnivore ecology and human-carnivore conflict. He is the author or co-author of several guides to wildlife tracking. ANDREW J. MARShall's primary research focus is the ecology and conservation of tropical forests and their vertebrate inhabitants, primarily in South-East Asia, and he is a member of the IUCN primate specialist group. 